\title{
Infective Endocarditis with No Underlying Disease for Which Bacterial Endophthalmitis Have Been the First Symptom
}

\author{
Marohito Nakata ${ }^{1}$, Tami Mashidori ${ }^{1}$, Namio Higa ${ }^{1}$, Mamoru Manita ${ }^{1}$, \\ Naomi Chibana ${ }^{2}$ and Kazuhiko Tabata ${ }^{1}$
}

\begin{abstract}
:
Bacterial endophthalmitis is a rare complication of infective endocarditis (IE). We herein report a case of IE with no underlying disease for which endophthalmitis could have been the first symptom. A 58-year-old man was admitted to our hospital with a fever, vision disturbances, and pain in the left hand joint. His left eye was removed because fusion on the cornea progressed. Streptococcus agalactiae was detected in blood cultures, fluid cultures from his left hand joint, and the removed eye. Bacterial endophthalmitis may present as the first symptom of IE and develop without underlying disease due to S. agalactiae infection.
\end{abstract}

Key words: infective endocarditis, bacterial endophthalmitis, septic emboli, Streptococcus agalactiae, aortic valve replacement

(Intern Med 59: 2061-2065, 2020)

(DOI: 10.2169/internalmedicine.6083-15)

\section{Introduction}

Bacterial endophthalmitis, which often presents with diabetes mellitus, heart valvular disease, renal function disorders, and neoplasias $(1,2)$, is rarely encountered as a complication of infective endocarditis (IE). We herein report a case of IE without any underlying disease for which bacterial endophthalmitis could have been the first symptom.

\section{Case Report}

This case involved a 58-year-old man with no medical history. Four days prior to hospital admission, he had a fever of $40^{\circ} \mathrm{C}$ with shaking and chills. The next day, backache and pain in the left hand joint appeared. The day before admission, vision in his left eye became dim and worsened, and finally he could not perceive light. He called for an ambulance due to the persistent fever and lack of vision in his left eye. On admission, his vital signs were as follows: blood pressure, 132/81 $\mathrm{mmHg}$; heart rate, $118 \mathrm{bpm}$; body temperature, $38.4^{\circ} \mathrm{C}$; and $\mathrm{SpO}_{2}, 97 \%$ (ambient air). A physi- cal examination showed a bloodshot conjunctiva, turbid cornea (Fig. 1), good oral hygiene, no rales, and no murmurs. The skin overlying his left hand joint was hot and swollen. Laboratory assessments on admission showed high Creactive protein levels (Table). According to these findings, we diagnosed the patient with bacterial endophthalmitis and bacterial arthritis caused by sepsis, however, the mode of bacterial entry was unknown; therefore, we administered cefmetazole and vancomycin. On the first day after admission, S. agalactiae was detected in blood cultures, thus we changed the antibiotic regimen to ampicillin (ABPC) 8 g per day. Antimicrobial drug susceptibility testing showed susceptibility to ABPC. We performed a contrast computed tomography scan from the chest to pelvis to search for the source of infection, but did not detect any abnormalities. Head magnetic resonance imaging was also performed, however, no findings suggesting septic emboli were observed. We subsequently suspected sepsis caused by IE and performed transthoracic echocardiography, but vegetation was not detected. We punctured his left swollen hand joint, and $S$. agalactiae was detected from the specimen. On the fourth day after admission, the patient underwent removal of the

${ }^{1}$ Department of Cardiology, Naha City Hospital, Japan and ${ }^{2}$ Department of General Internal Medicine, Naha City Hospital, Japan Received for publication October 28, 2015; Accepted for publication February 1, 2016 Correspondence to Dr. Kazuhiko Tabata, 39hiko-naha@nch.naha.okinawa.jp 
Table. Laboratory on Admission.

\begin{tabular}{llllll}
\hline WBC & 9,400 & $/ \mu \mathrm{L}$ & T-Bil & 2.4 & $\mathrm{mg} / \mathrm{dL}$ \\
$\mathrm{RBC}$ & $461 \times 10^{4}$ & $/ \mu \mathrm{L}$ & $\mathrm{AST}$ & 35 & $\mathrm{IU} / \mathrm{L}$ \\
$\mathrm{Hb}$ & 15.0 & $\mathrm{~g} / \mathrm{dL}$ & $\mathrm{ALT}$ & 60 & $\mathrm{IU} / \mathrm{L}$ \\
$\mathrm{Ht}$ & 41.5 & $\%$ & $\mathrm{ALP}$ & 700 & $\mathrm{IU} / \mathrm{L}$ \\
$\mathrm{Plt}$ & $14.9 \times 10^{4}$ & $/ \mu \mathrm{L}$ & $\mathrm{LDH}$ & 217 & $\mathrm{IU} / \mathrm{L}$ \\
& & & $\gamma-\mathrm{GTP}$ & 170 & $\mathrm{IU} / \mathrm{L}$ \\
$\mathrm{Na}$ & 135 & $\mathrm{mEq} / \mathrm{L}$ & $\mathrm{CK}$ & 24 & $\mathrm{IU} / \mathrm{L}$ \\
$\mathrm{K}$ & 3.1 & $\mathrm{mEq} / \mathrm{L}$ & & & \\
$\mathrm{Cl}$ & 106 & $\mathrm{mEq} / \mathrm{L}$ & $\mathrm{CRP}$ & 27.30 & $\mathrm{mg} / \mathrm{dL}$ \\
$\mathrm{BUN}$ & 21.8 & $\mathrm{mg} / \mathrm{dL}$ & & & \\
$\mathrm{Cre}$ & 0.87 & $\mathrm{mg} / \mathrm{dL}$ & Influenza A(-), B(-) & \\
& & & & & \\
$\mathrm{HbA} 1 \mathrm{c}$ & 6.5 & & Blood culture & Streptococcus agalactiae \\
\hline
\end{tabular}

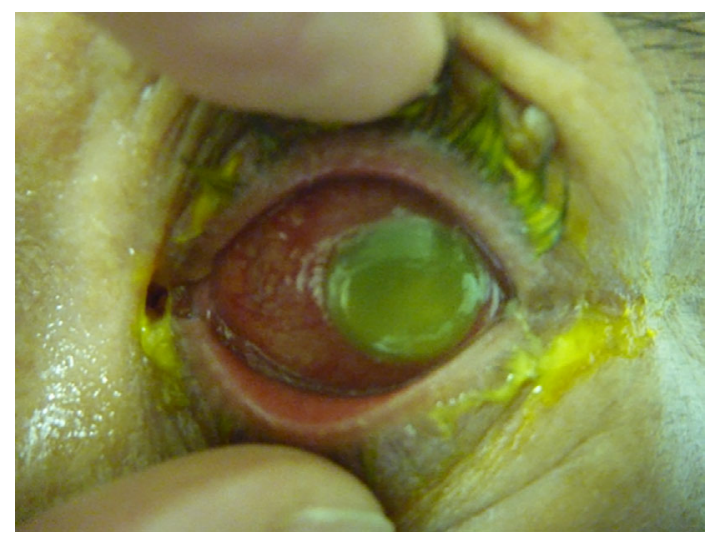

Figure 1. Initial views of the left eye.

left eye because the fusion on the cornea progressed (Fig. 2). S. agalactiae was detected in the eye. His general condition improved after ABPC administration (Fig. 3). On day 12 after admission, transesophageal echocardiography did not reveal vegetation, however, noncoronary cusp (NCC) valve prolapse was observed (Fig. 4); therefore, IE was suspected. Aortic regurgitation was mild. One week later, transthoracic echocardiography revealed moderate aortic regurgitation; thus, the regurgitation had worsened. His condition progressively worsened thereafter, and the onset of dyspnea led us to take a chest radiograph, which showed congestion and indicated a diagnosis of heart failure. Thirtyone days after admission, we performed transesophageal echocardiography again and confirmed the presence of severe aortic regurgitation and vegetation (Fig. 5). Since the regurgitation had worsened and congestive heart failure occurred, we judged that an operation was necessary. We performed aortic valve replacement and noted that the NCC valve tip was destroyed, and we saw a hole at the intercoronary (right coronary-left coronary) commissure (Fig. 6, 7). However, the structure that we thought was vegetation was a destroyed NCC valve tip. No bacteria were detected in a culture of the extracted valve. The patient's clinical course

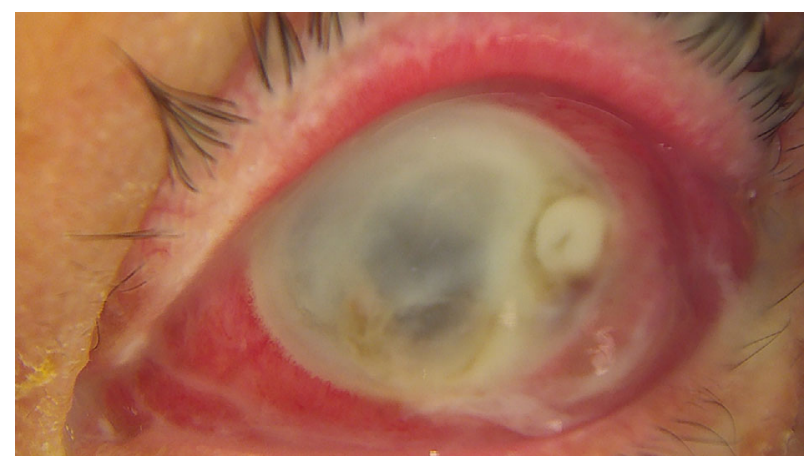

Figure 2. View of the left eye on the fourth day after admission. The fusion on the cornea progressed.

did not show any postoperative complications, and he was discharged 11 days after the operation.

\section{Discussion}

This case demonstrates two predominant points. First, IE with bacterial endophthalmitis as the first symptom does indeed exist. Second, in cases of S. agalactiae IE, valve destruction can often rapidly occur, leading to high mortality rates.

In the present case, IE presented with bacterial endophthalmitis as the first symptom. However, previous reports have only described cases of $S$. agalactiae IE that were complicated with bacterial endophthalmitis (3). According to the Duke criteria, this case met 1 major criterion (new valvular regurgitation) and 1 minor criterion (a fever above $38.0^{\circ} \mathrm{C}$ ), which did not lead to a definitive diagnosis. However, pain in the left hand joint appeared one day after the fever occurred. Thus, according to this medical history, the fever was caused by IE. Bacterial arthritis and bacterial endophthalmitis occurred due to IE septic emboli. Bacterial endophthalmitis is classified as endogenous or exogenous. Endogenous bacterial endophthalmitis is a rare condition that affects individuals of any age and represents $2-15 \%$ of 


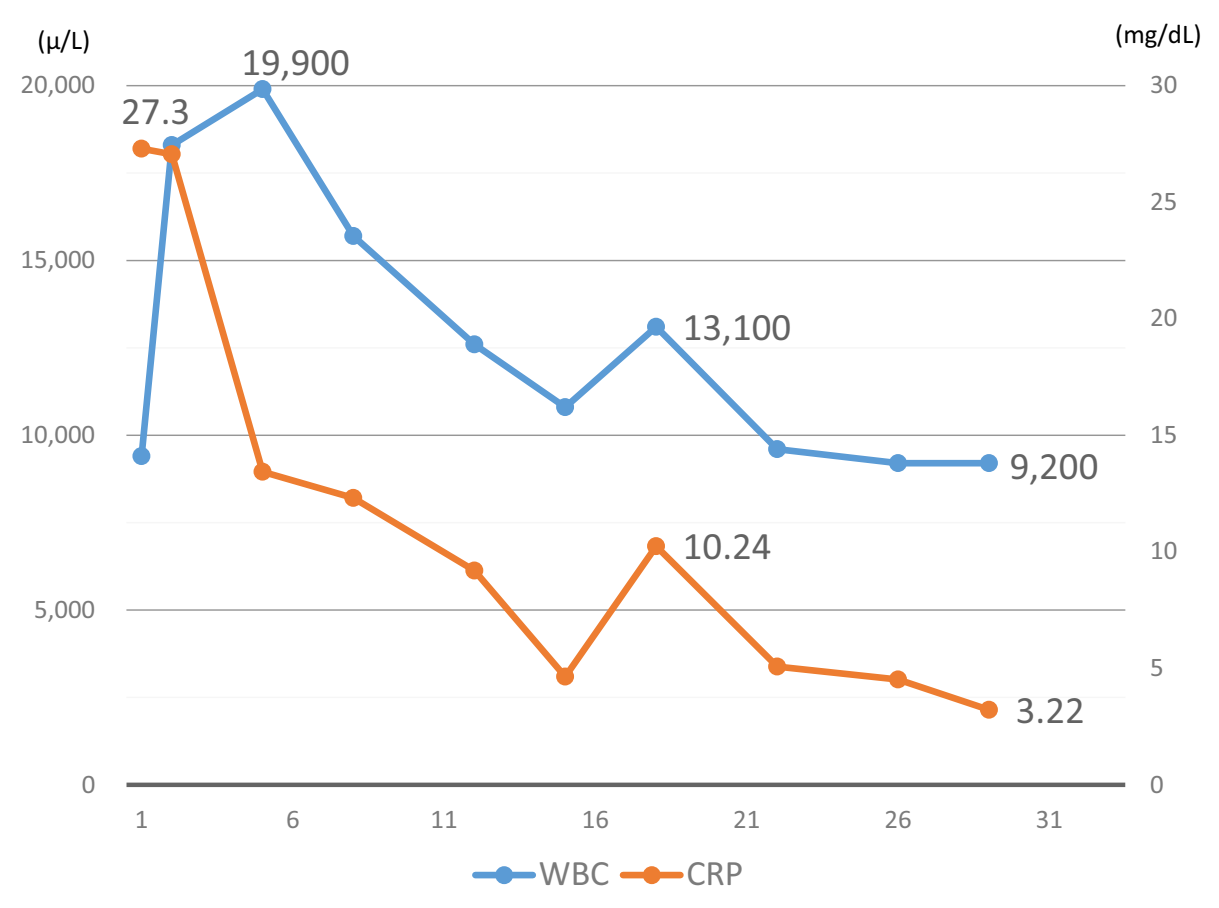

( $\left.{ }^{\circ} \mathrm{C}\right)$

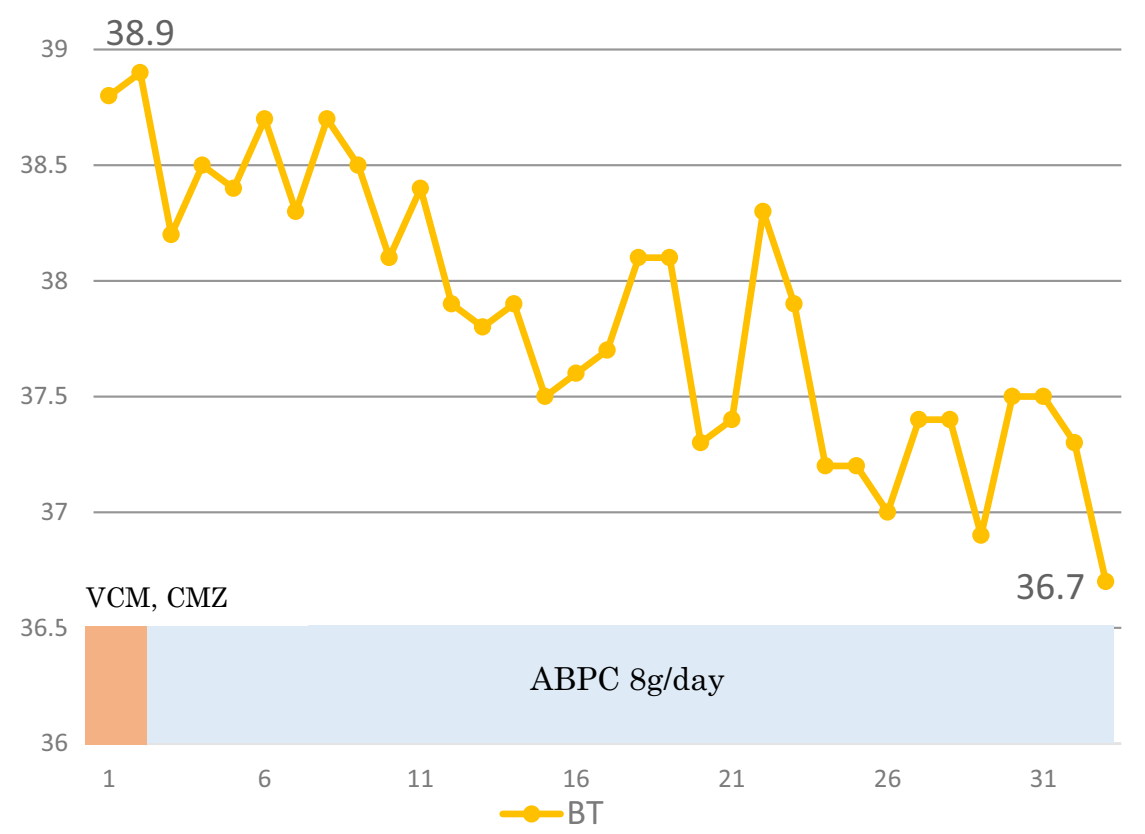

$\begin{array}{llllll}\text { Culture } & \uparrow \uparrow & \uparrow & \uparrow & \uparrow & \uparrow \\ \text { blood (+) (-) } & (-) & (-) & (-) & (-) \\ \text { hand joint (+) } & & & & \\ \text { left eye } & (+) & & \end{array}$

Figure 3. Clinical course. Progression of the inflammatory reaction and body temperature is shown.

all cases of endophthalmitis (4). On average, endogenous endophthalmitis occurs in only 5 of every 10,000 hospitalized patients (4). The common causes of endogenous endophthalmitis are meningitis, endocarditis, urinary tract infection, and wound infection (5). The most common cause in two-thirds of the infections was Gram-positive bacteria. Although the most common agent was Staphylococcus aureus (25\% of patients), the most common group was Streptococcus $(32 \%)$. The onset of the signs and symptoms of endophthalmitis is dependent on pathogenic virulence. 

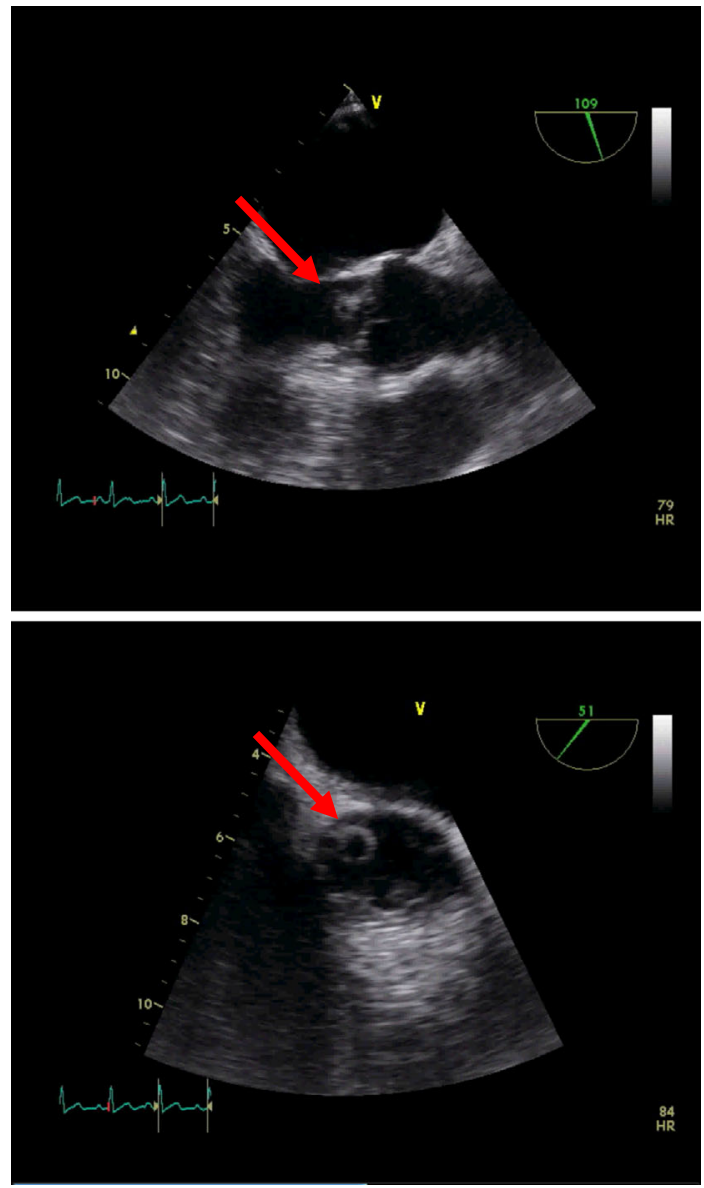

Figure 4. Transesophageal echocardiography performed on day 12 after admission. The arrows show noncoronary cusp (NCC) valve prolapse.

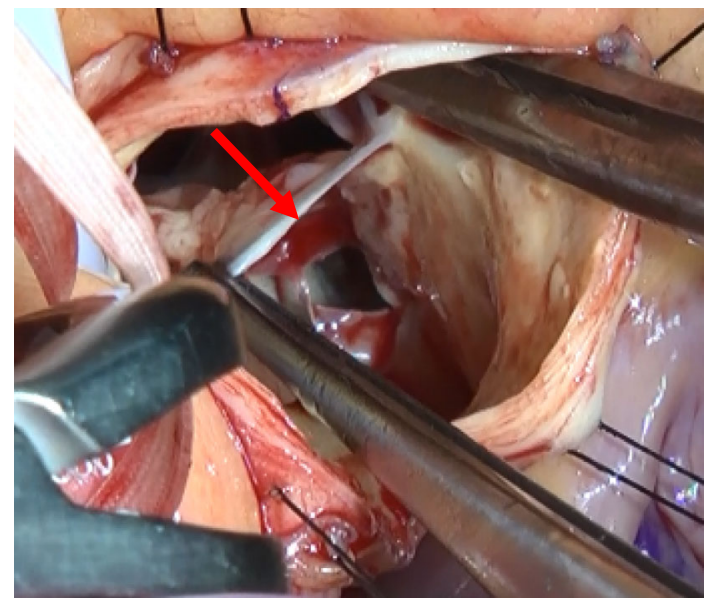

Figure 6. The arrow shows that there was a hole in an aortic valve.

Streptococcal infection is generally related to a fulminating process with pain that progressively worsens and presents with chemosis, proptosis, hypopyon, and corneal melting (6). Endogenous endophthalmitis caused by group B Streptococcus is rarely reported in adults and almost exclusively related to IE (7). S. agalactiae belongs to group B
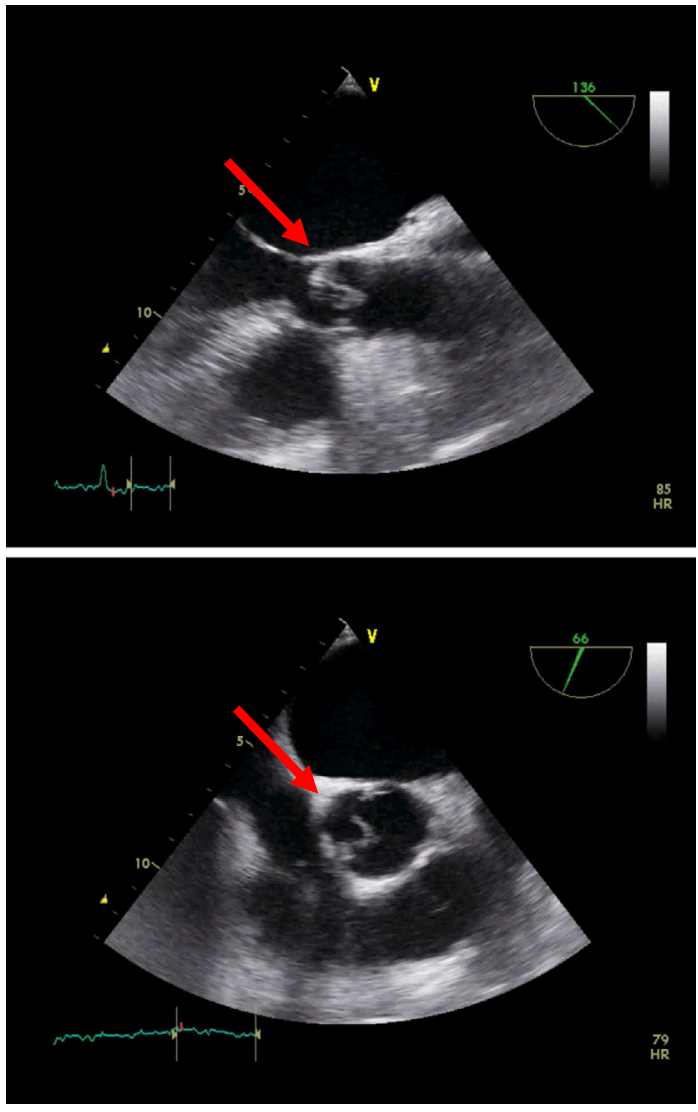

Figure 5. Transesophageal echocardiography performed on day 31 after admission. The arrows show vegetation, however, this structure that was presumed to be vegetation was actually a destroyed NCC valve tip.

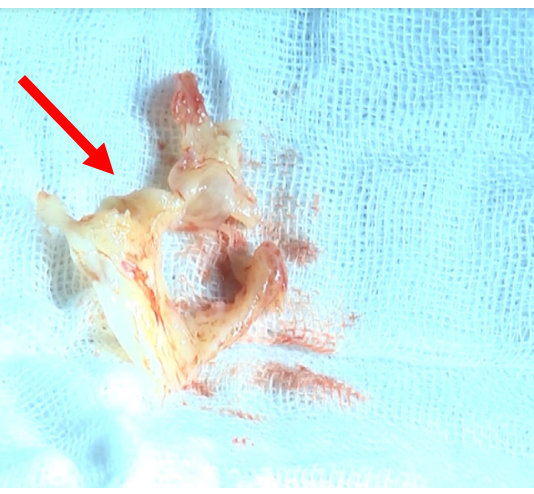

Figure 7. The removed aortic valve observed from the left ventricular side. A hole could be seen.

Streptococcus. In the present case, endophthalmitis occurred in the left eye. The right eye is generally more often affected than the left eye, which is likely due to direct blood flow from the heart (6).

Sambola et al. (8) reviewed 30 cases of $S$. agalactiae IE and found that the overall incidence of IE caused by $S$. agalactiae is $1.7 \%$, and a mean of 0.12 episodes of $S$. agalactiae IE has been noted per 10,000 hospital admissions. The mitral valve was most frequently involved (50\%), followed by the aortic valve, both the mitral and aortic valves, and 
the tricuspid valve. Among patients with native valve IE caused by S. agalactiae, $30 \%$ had local complications: $57 \%$ had ruptured cords, $29 \%$ had cusp perforation and disruption of the annular structure, and $14 \%$ had abscess. Heart failure developed in $67 \%$ of the patients. Embolisms were present at the time of admission to the hospital or developed while in the hospital in $50 \%$ of patients, with the following distribution: cerebral embolism (in $47 \%$ of patients), septic arthritis $(13 \%)$, and endophthalmitis (13\%). In S. agalactiae IE, large vegetations or valvular destruction are common (9-11). The large size of the vegetations and their friability may explain the high rate of systemic emboli (9-11). The lack of $S$. agalactiae fibrinolysin production in the vegetations might also account for the pathogenesis of this complication. $S$. agalactiae can attach to a normal valve and rapidly multiply, thus IE can occur without underlying heart diseases or dental procedures (12). Surgical valve replacement was performed a median of 19 days after admission to the hospital. The mortality rate of patients with native valve IE was $36 \%$. In the present case, we detected that the NCC valve tip was prolapsed 12 days after admission and destroyed 31 days after admission. Thus, the NCC valve tip was destroyed within 19 days. As shown above, S. agalactiae IE is an aggressive disease, and $29 \%$ of cases show cusp perforation. In our case, the patient's white cell count fell below 10,000/ $\mu \mathrm{L}$ within 22 days. The C-reactive protein level gradually decreased, but remained high. It is unclear why inflammation persisted and valve destruction progressed despite appropriate antibiotic use. It is possible that a microabscess formed in the NCC, thus inflammation continued. However, we could not confirm this hypothesis because we did not perform a pathological examination.

In summary, IE exists in conjunction with bacterial endophthalmitis as the first symptom, and $S$. agalactiae endocarditis is an uncommon but aggressive disease, requiring prompt valve replacement. To establish the pathogen, a culture examination is essential.

The authors state that they have no Conflict of Interest (COI).

\section{References}

1. Meredith TA. Clinical microbiology of infectious endophthalmitis. In: Retina. 2nd ed. Ryan SJ, Ed. Mosby, St. Louis, 1994: v.l, chapter16.

2. Sivalingam A, Bolling J, Goldberg RE, et al. Ocular abnormalities in acquired heart disease. In: Duane's Clinical Ophthalmology, Vol. 5. Tasman W, Jaeger EA, Eds. JB Lippincott, Philadelphia, 1998: ch. 22.

3. Seno T, Nishiue T, Nakamura $S$, et al. Infective endocarditis complicating bilateral bacterial ophthalmitis: a case report. Nihon Shinzo Kekkan Geka Gakkai Zasshi (J Cardiol) 39: 171-176, 2002 (in Japanese).

4. Jackson TL, Eykyn SJ, Graham EM, Stanford MR. Endogenous bacterial endophthalmitis: a 17 -year prospective series and review of 267 reported cases. Surv Ophthalmol 48: 403-423, 2003.

5. Wong JS, Chan TK, Lee HM, Chee SP. Endogenous bacterial endophthalmitis: an east Asian experience and a reappraisal of a severe ocular affliction. Ophthalmology 107: 1483-1491, 2000.

6. Forster RK. Endophthalmitis. In: Duane's Clinical Ophthalmology, Vol. 4. Tasman W, Jaeger EA, Eds. JB Lippincott, Philadelphia, 1998: ch. 24

7. Nagelberg HP, Petashnick DE, To KW, Woodcome HA Jr. Group B streptococcal metastatic endophthalmitis. Am J Ophthalmol 117: 498-500, 1994.

8. Sambola A, Miro JM, Tornos MP, et al. Streptococcus agalactiae infective endocarditis: analysis of 30 cases and review of the literature, 1962-1998. Clin Infect Dis 34: 1576-1584, 2002.

9. Gallagher PG, Watanakunakorn CH. Group B streptococcal endocarditis: report of seven cases and review of the literature, 19621985. Rev Infect Dis 8: 175-188, 1986.

10. Scully BE, Spriggs D, Neu HC. Streptococcus agalactiae (group B) endocarditis: a description of twelve cases and review of the literature. Infection 15: 169-176, 1987.

11. Baddour LM. Infective endocarditis caused by $\beta$-hemolytic streptococci. The Infectious Diseases Society of America's Emerging Infections Network. Clin Infect Dis 26: 66-71, 1998.

12. Pringle SD, McCartney AC, Marshall AS, Cobbe SM. Infective endocarditis caused by Streptococcus agalactiae. Int J Cardiol 24: 179-183, 1989.

The Internal Medicine is an Open Access journal distributed under the Creative Commons Attribution-NonCommercial-NoDerivatives 4.0 International License. To view the details of this license, please visit (https://creativecommons.org/licenses/ by-nc-nd/4.0/).

(C) 2020 The Japanese Society of Internal Medicine Intern Med 59: 2061-2065, 2020 